\title{
Combined anaesthesia in patients undergoing surgery for ischemic heart disease
}

\section{Volchkov V., Boyarkin A., Sizov O., Malshakov V., Balandina E., Volchkova E.}

\author{
St. Petersburg State University, Dept of Anaesthesiology \& Intensive Care; City Multifield \\ Hospital №2, Dept of Anaesthesiology \& Intensive Care; Pavlov First Saint Petersburg Medical \\ University, Dept of Anaesthesiology \& Intensive Care, Saint Petersburg, Russian Federation
}

Goal of Study: In recent years appeared a large number of works devoted to the cardioprotective effect of inhalation anaesthetics and epidural anaesthesia. The goal of study was to compare the effects of different types of anaesthetic management of cardiovascular operations for close outcome results.

Materials and Methods: The study involved 122 patients who underwent surgical treatment for ischemic heart disease under conditions of artificial circulation. Patients were randomized into two comparable groups depending on the type of anaesthesia. First group included 56 patients, who were operated on under combined anaesthesia (thoracic epidural anaesthesia with intravenous infusion of propofol controlled by the target concentration). Second group included 66 patients who were operated on under multicomponent general anaesthesia (sevoflurane inhalation with intravenous infusion of fentanyl and propofol controlled by the target concentration). Evaluated indices: volume load during the operation and in early postoperative period, the dose of used inotropic support, the level of troponin I and brain natriuretic peptide (BNP) in patients after surgery. The frequency of development of complications and the duration of inpatient stay in hospital were analyzed.

\begin{tabular}{|l|c|c|}
\hline \multicolumn{1}{|c|}{ Significative } & Group 1 & Group 2 \\
\hline Gender FlM & $15 \backslash 41$ & $20 \backslash 46$ \\
\hline Age & $65,0 \pm 8,5$ & $63,4 \pm 8,3$ \\
\hline Weight & $82,0 \pm 1,3$ & $81,5 \pm 1,3$ \\
\hline $\begin{array}{l}\text { Duration of } \\
\text { cardiopulmonary } \\
\text { bypass }\end{array}$ & $58,9 \pm 14,1$ & $67,7 \pm 29,4$ \\
\hline Aortic clamping time & $34,0 \pm 8,8$ & $38,7 \pm 9,3$ \\
\hline $\begin{array}{l}\text { Duration of operation } \\
\text { (Operation time) }\end{array}$ & $246,6 \pm 37,9$ & $240,6 \pm 36,5$ \\
\hline
\end{tabular}

Results and Discussion: The infusion therapy total demand during the operation in the two compared groups did not differ significantly. Preload indices in both groups were comparable before operation and declined slightly postoperatively. Along with this no statistically significant differences between groups were detected. Inotropic support was used unreliably more often in the group of combined epidural-intravenous anaesthesia. The concentration of troponin I in the postoperative period increased in the interval of time from 1 to 24 hours after surgery in both groups $(p>0,05)$. BNP also increased after the intervention in both groups. There were no substantial differences in the frequency of development of cardiovascular disorders. Patients with epidural anaesthesia were extubated earlier and had less pronounced pain syndrome. However, the average time of postoperative stay in the intensive care unit and in hospital in both groups did not differ significantly.

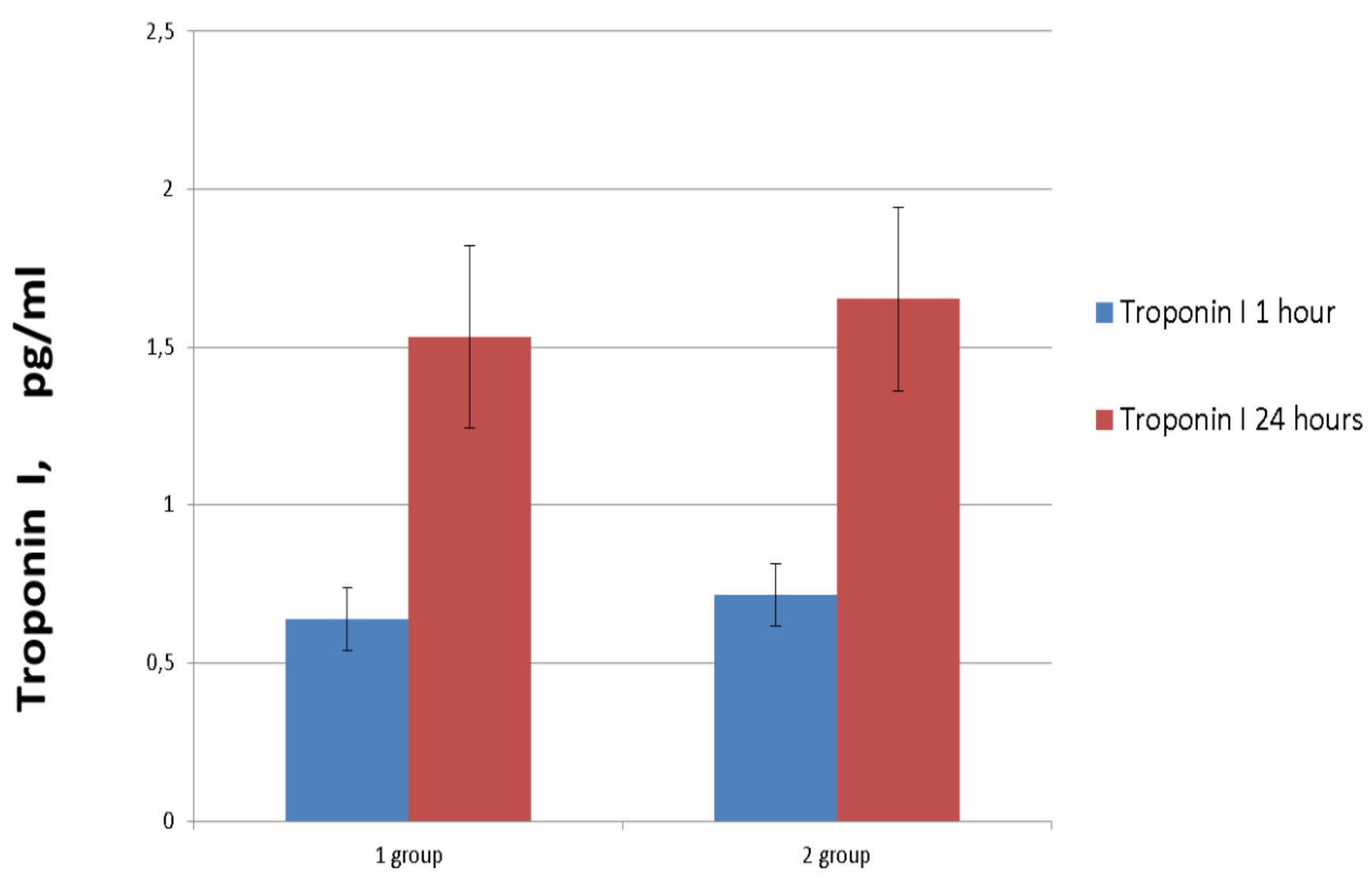

Dynamics of changes in the troponin level after surgery, $\mathrm{pg} / \mathrm{ml}(\mathrm{M} \pm \mathrm{m})$

Conclusions: Both methods of anaesthetic management can be used successfully in coronary artery bypass surgery in conditions of artificial blood circulation. 